
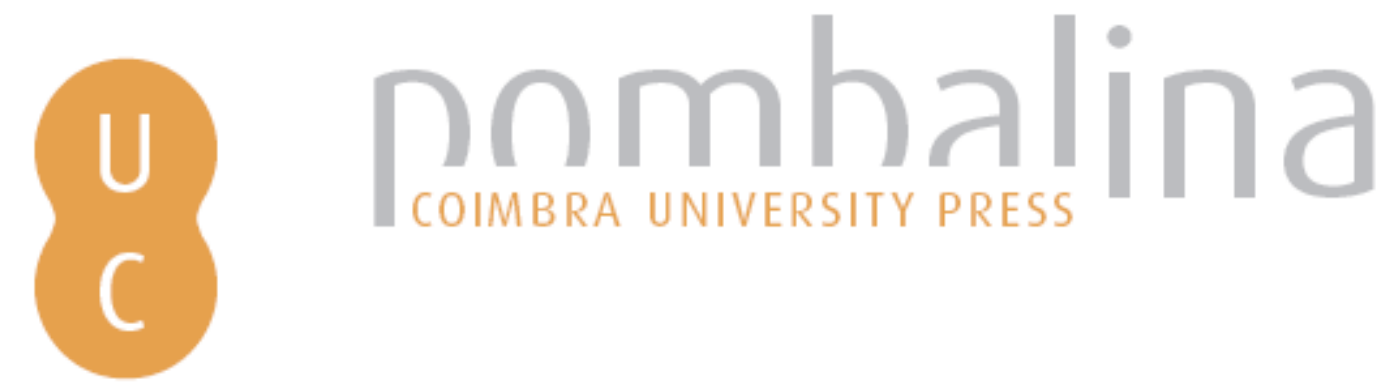

\title{
Mythologiai-Mythologemata: irredectubilidad del mito en la dramaturgia latinoamericana (Eestudio del teatro de León Febres-Cordero)
}

Autor(es): Dimeo Álvarez, Carlos

Publicado por: Imprensa da Universidade de Coimbra; Annablume

URL

persistente: URI:http://hdl.handle.net/10316.2/40929

DOI: $\quad$ DOI:https://doi.org/10.14195/978-989-26-1298-0_23

Accessed : $\quad$ 26-Apr-2023 15:56:12

A navegação consulta e descarregamento dos títulos inseridos nas Bibliotecas Digitais UC Digitalis, UC Pombalina e UC Impactum, pressupõem a aceitação plena e sem reservas dos Termos e Condições de Uso destas Bibliotecas Digitais, disponíveis em https://digitalis.uc.pt/pt-pt/termos.

Conforme exposto nos referidos Termos e Condições de Uso, o descarregamento de títulos de acesso restrito requer uma licença válida de autorização devendo o utilizador aceder ao(s) documento(s) a partir de um endereço de IP da instituição detentora da supramencionada licença.

Ao utilizador é apenas permitido o descarregamento para uso pessoal, pelo que o emprego do(s) título(s) descarregado(s) para outro fim, designadamente comercial, carece de autorização do respetivo autor ou editor da obra.

Na medida em que todas as obras da UC Digitalis se encontram protegidas pelo Código do Direito de Autor e Direitos Conexos e demais legislação aplicável, toda a cópia, parcial ou total, deste documento, nos casos em que é legalmente admitida, deverá conter ou fazer-se acompanhar por este aviso.

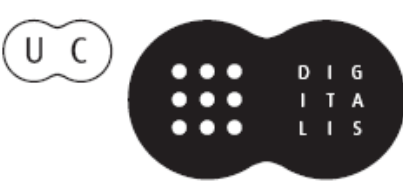




\section{O Livro do Tempo: \\ Escritas e reescritas}

\section{Teatro Greco-Latino e sua recepção II}

Maria de Fátima Silva, Maria do Céu

Fialho \& José Luís Brandão (coords.)

IMPRENSA DA UNIVERSIDADE DE COIMBRA 


\title{
MYTHOLOGIAI-MYTHOLOGEMATA ${ }^{\mathrm{I}}$ : IRREDECTUBILIDAD DEL Mito EN LA DRAMATURGIA LATINOAMERICANA (ESTUDIO DEL TEATRO de León Febres-Cordero)
}

\section{[Mythologiai-Mythologemata: Irreductibility of the myth in Latin-American dramaturgy (Study of León Febres-Cordero's theatre]}

\author{
Carlos Dimeo Álvarez (cdimeo@Ath.bielsko.pl) \\ Universidad de Bielsko-Biaea \\ Akademia Techniczno-Humanistyczna w Bielsku-Biaeej
}

Resumen - El filósofo húngaro Karl Kerényi asegura que cada mito y su interpretación están "estigmatizados" por una "materia especial” de traducción de sí mismos. Esta materialidad y a la vez corporeidad de sus estructuras, ha sido legada a través del tiempo en diferentes tipos de narraciones (el teatro fue una de las formas "narrativas" más utilizadas para ello). La materia especial del mito y su fondo "histórico" es lo que Kerényi enclava en las categorías mythologiai-mythologemata. A partir de estos postulados teóricos, queremos estudiar cómo y de que manera se han interpretado y reinterpretado ciertos mitos griegos en el teatro clásico griego y así transferidos como materialidades poéticas en la dramaturgia latinoamericana. Para ello en esta presentación nos serviremos de las tragedias del autor venezolano León Ezequiel Febres-Cordero, El último minotauro (1999), Clitemnestra (1999) y Penteo (2002).

Palabras clave - Mytologiai-Mytologemata, mito, religión, poesía, teatro latinoamericano, teatro clásico antiguo, teatro griego antiguo.

Авsтract - The Hungarian philosopher Karl Kerényi ensures that every myth and its interpretation are "stigmatized" by a "special material" translation themselves. This materiality and corporeality while their structures, has been bequeathed over time in different narratives (the theatre was one of the "narratives" forms used for this). The special subject of myth and its background "historical" is what Kerényi locked in categories mythologiai - mythologemata. From these theoretical postulates, we want to study how and in what way have been interpreted and reinterpreted certain Greek myths in classical theatre and thus transferred as poetic materiality's in Latin American playwriting. To do so in this presentation we will use the tragedies of the Venezuelan author Leon Febres-Cordero, El ultimo minotauro (1999), Clitemnestra (1999) and Penteo (2002).

KeYwords - Mytologiai-Mytologemata, myth, religion, poetry, Latin American theater, classical ancient theater, ancient Greek theater.

${ }^{1}$ Según las categorías definidas por Karl Kerényi en: Kerényi, K. ( $\left.{ }^{2} 2012\right)$, La religión antigua. Trad. Adan Kovacsics, Mario León. Barcelona: Editorial Herder. 


\section{De la MATERia SUSTANCIAL Del Mito, LA TRAgedia y EL DRAMA}

El filósofo húngaro Károly Kerényi asegura que cada mito, así como la manera de interpretárseles con frecuencia se hallan "estigmatizados" por una "materia especial” de traducción de los mismos. Esta percepción que corrobora la persistente presencia de un "velo cobertor", que encubre la esencia "divina" de la narración, se asienta en una tradición que forja a su vez el sentido mitológico del propio "mitologema". La substancia propiamente metafórica de su fuerza descriptiva, así como el poder "transformacional" de su discurso (en cierto momento el mito es palabra sagrada o mágica) radican en que la vida (durante lo mítico) no está basada ni en la experiencia, ni en el fundamento de un espíritu racionalista. Obviamente que el comportamiento que se deriva de los hombres no es irracional, pero no juega tampoco en modo alguno, sobre la base de una obsesiva y pretendida racionalidad. Si algo nos habla el mito, es de la capacidad que tenemos los hombres para dejarnos llevar por la pasión, que no es lo irracional desenfrenado, sino una basta cualidad humana para creer. De manera tal que el mito actúa y persiste bajo los signos de la creencia, de la fe, y no así de la razón (que pertenece a una otra lógica discursiva). Por lo tanto, el mitologema (o el quid pro quo que se abroga el mitologema) no es más que el sustrato esencial del relato que se ha hendido/hundido profundamente en la raíz mítica de la historia, así como también en el centro propio de su materialidad. A la vez, la corporalidad de sus estructuras "mitogémicas" ${ }^{3}$ ha sido legada a través del tiempo en diferentes tipos de narraciones.

Ahora bien, de todo esto se desprende la pregunta, ¿En qué sentido el legado del teatro podría haber otorgado al mito un espacio donde colocara todo el poder narrativo que le convoca? $Y$ ¿si es tanta la fuerza de su poder como para que el teatro mismo se convierta, por excelencia, en la forma decisiva y en el vehículo de su materialidad? Si tal como afirma Kerényi, el mito es canción y poesía, o al menos está nutrido por ellas, es posible pensar que el teatro consiguiera en un momento determinado equilibrar estas distancias, disparidades, discrepancias o secuencias y juntarlas en una sola forma "descriptiva". De tal manera que en muchos "episodios" y fragmentos de los trágicos griegos, un doble o triple esquema se forjó. El dramaturgo consigue enlazar dos estructuras diferentes (o tres inclusive). Es decir, el drama, el canto y la poesía. El drama que en su devenir se transforma en la tragedia. Claros son los ejemplos de Esquilo, Sófocles, Eurípides, Menandro, o incluso de los trágicos latinos y romanos tales como Livio Andrónico (280-204 a. C.) o Lucio Séneca (4 a.C. - 65 d. C.) etc.

\footnotetext{
${ }^{2}$ Kerényi et alii 1998: 15.

${ }^{3}$ Con "mitogémicas" queremos decir no mitológicas (aunque su raíz derive de allí) no los mitos, en tanto y en cuanto narración, sino particularmente narrativas del sustrato mítico. En otras palabras la esencia y el valor primigenio del relato.
} 
En consecuencia no habrá tragedia sin texto. Es el texto un vehículo portador de lo trágico, un médium factum para expresarlo. Y los trágicos griegos ocuparon buena parte de su dramaturgia fundados sobre la base de sus propios relatos.

La palabra griega mythologia contiene el sentido no solo de "cuentos" (mythoi), sino también el de "contar" (legein): un tipo de narración que originalmente también despertaba ecos, porque promovía el darse cuenta de que la historia contada concernía personalmente al narrador y a la audiencia. Si queremos devolver vida plena a la "materia muerta" de los fragmentos de mitología griega que nos han quedado, tenemos que reponerlos en el ámbito de aquella narración y de aquella participación de la audiencia ${ }^{4}$.

Estas afirmaciones nos hacen constar que la presencia estructural simbólica de ciertas características que posee el relato son materia precisa para lo trágico. Ello justifica la presencia de Kerényi y sus tesis para finalmente comprender que la obra de un autor, uno que en este caso está fuera (evidentemente) de todo ese contexto (tal como es el caso de León Febres-Cordero), pueda reconstituir lo mitológico y lo trágico.

En efecto la dramaturgia del autor venezolano adquiere prontamente esa capacidad sutil del discurso dramático que vuelve a la obra, o por una vía (propiamente la del drama), o por otra vía (explícitamente la de la comedia), o simplemente por una tercera vía excepcionalmente: trágica. Y tal como Kerényi afirma, la materia del relato, dicho con más exactitud, está muerta ${ }^{5}$, sólo que el narrador, el poeta, el dramaturgo, el intérprete es capaz de devolverle a aquel ámbito una existencia, que no tuviera, si no apareciera un medio de interpretación.

Sin embargo, el "narrador" le devuelve la vida en tanto y en cuanto reactualiza la esencia particular de ese texto "anclado" en tiempo y espacio, en una memoria "antigua". El mito es un logos detenido en el tiempo que se recuerda "más o menos" y que se va redescubriendo en la medida en que los "cantores" lo evocan. Esta parece ser en esencia de la evocación que trae Febres-Cordero en la tres piezas que intentamos presentar aquí. Se trata de la recuperación de una crítica substantiva tanto en la psique individual de los "sujetos", así como en la reconstrucción histórica, y memoria de una contemporaneidad según la cual puede mostrarnos su actualización.

\section{LA PREGUNTA POR LA MATERIALIDAD MISMA DEL MITO Y DEL TEATRO}

Se ha debatido mucho en torno a la cualidad (conspicua por demás) de la performatividad del teatro. A la vez se ha afirmado sustantivamente que el teatro debe apegarse a un sentido de teatralidad. Sin embargo, parece imprescindible

\footnotetext{
${ }^{4}$ Kerényi 1997: 15.

${ }^{5}$ Cf. Kerényi 1997: 18.
} 
hacer un alto aquí para comprender esto con una mayor precisión. La cualidad "teatral" del teatro, es probable que esté sostenida por un elemento o valor dramático que se describe como el sustrato inmanente del "relato". A diferencia de lo que muchos teóricos seguramente podrán afirmar, partiremos de que la base sustancial del texto dramático es el texto mismo. Y de que no hay teatro sin texto.

Es por ello que después de la oda, la canción (sagrada y religiosa), la revelación mística del poeta en la poesía; el teatro, por supuesto, pareciera ser una de las formas "narratorias" que más se han utilizado para ello y a la vez que más se ajusta a los juegos de enigmas, metafóricos y parabólicos que poseen los mitos. Los ejemplos están claros asentándose en la tonalidad profética del coro griego, o del héroe, o incluso del dios.

De esta manera es que podemos comprender que la materia especial del mito junto a su fondo relativamente "histórico" es aquello que Kerényi enclavó en las categorías mythologiai - mythologemata. La primera contiene el tema, la idea (v. g. el mito de Edipo) y la segunda representa la estructura misma del texto narrado.

A partir de estos postulados teóricos, queremos estudiar cómo y de que manera se han interpretado o incluso reinterpretado ciertos mitos del teatro clásico griego, y así transferidos como materialidad poética en la dramaturgia latinoamericana. Dicho de otra forma, se pretende llevar a cabo el análisis de un cuerpo dramatúrgico (en específico que se condensa en el teatro latinoamericano hoy) y entender cómo "reinterpreta" la tragedia antigua y clásica griega o además hace un nuevo modelo de lo trágico ${ }^{6}$. Para ello en este trabajo nos serviremos de un drama y dos "tragedias" del autor venezolano León Ezequiel Febres-Cordero contenidas en el volumen Teatro de editorial Verbum, a saber los textos El último minotauro (1999), Clitemnestra (1999) y Penteo (2002). Aunque de los tres textos mencionados solo haremos énfasis (por razones lógicas de espacio del trabajo) en El último minotauro en el entendido de que las tres resumen el valor categorial que poseen los mitos en su estructura.

Nos proponemos pues así, abordar cómo ha sido la construcción de ciertos modelos teatrales y escénicos clásicos que se escenifican a través de los mitos griegos en el teatro latinoamericano, ya que según el propio Febres-Cordero, "Los griegos no hablaban de mitos. Ellos lo que hacían era hablar en mito" ${ }^{8}$ Y a partir de allí, preguntarnos si (en todo caso) podríamos asegurar que un mito no se habla, sino que emblemáticamente se cuenta. La "ciencia de la mitología"

\footnotetext{
${ }^{6}$ Entendiendo aquí lo trágico en el sentido griego, y no por ejemplo, en el sentido isabelino.

${ }^{7}$ En referencia a El último minotauro, León Febres-Cordero nos presenta esta obra en realidad no como una tragedia sino como un drama satírico.

${ }^{8}$ Agathos 2010: 76.

${ }^{9}$ Kerényi, K., B. Kiemann, B. 2011.
} 
expondría entonces que la verdadera corriente de todo mito se asegura a través de sus posibles combinaciones o variantes, las cuales dan a la representación del mismo una reticente y obstinada reiteración/repetición de los acontecimientos, fórmula narrativa que se trastoca en tiempo y espacio.

Al contrario de lo que algunos pueden suponer, un mito no se rompe, no se corta, se reconstruye ad eternum, incluso (si se quiere) metamorfoseándose incansablemente hasta la saciedad. A la vez que la permanente recursividad de las narraciones que trasiegan en un mito lo mantienen vivo y lo fijan en la memoria colectiva como un sello acaudalado de arquetipos, imágenes, símbolos y estructuras "mistéricas" y sagradas, la dramaturgia parece ser un género especial hoy en día para la reconfirmación del texto mítico que es en sí un texto sagrado. ¿Serán entonces estas formas las que nos permitirán reconstruir la estructura narrativa usada en el teatro clásico antiguo como una historia sustantiva y real? $¿$ E1 teatro reconstruye un modelo vivido o toma estas fuentes para reconstituirse como un modo de (re)presentación de "lo real" en escena? ¿Es posible hallar una reinterpretación de lo mítico en el teatro latinoamericano contemporáneo que se corresponda en profundidad con las formas del teatro griego antiguo?

Históricamente, tanto como en otras tradiciones teatrales, ha habido en América Latina un cúmulo de "representaciones", textos dramáticos y puestas en escena que se han acercado "vorazmente" a los temas de la mitología, tanto aquellas que corresponden a la esfera de lo tradicional, autóctono y popular, como las que se fundamentan en los mitos griegos. A partir de allí, este aluvión de construcciones poéticas junto con sus respectivas formas espectaculares nos remiten directamente (aunque sin quererlo) al furtivo intento de rastrear el carácter metafísico de la "existencia". En este sentido debemos decir que el mito se revierte como un controvertido discurso pleno de inestabilidad.

En el texto de Karl Kerényi, se hace referencia al, aún todavía, carácter incomprendido de la cultura minoica. El autor húngaro toma esta idea a partir de que al hacerse la pregunta por la existencia de un dios griego o uno cristiano (por supuesto basado en la fundamentación de ateísmo filosófico nietzschiano), el filósofo-filólogo alemán ha traído hasta los lectores la cuestión fundamental para entender el problema de la raíz de la cultura griega. Esto significa que el conflicto surgido a partir de aquí (según entonces apunta Kerényi) es que sin antes poder "responder a la pregunta “¿qué es dionisíaco?” los griegos serán del todo desconocidos e inimaginables (...)" ${ }^{10}$.

No obstante, aquí no está, al menos desde la perspectiva hacia la queremos orientarnos, la fundamentación de nuestro problema. No queremos desplazar el lugar esencial del conflicto escénico al marco de lo que fue la cultura minoica

\footnotetext{
${ }^{10}$ Kerényi. et al. 1998: 9.
} 
(subyacente como un origen epistemológico de, a su vez, la cultura cretense ${ }^{11}$ y en consecuencia de la gran cultura griega) y de lo que para ella fue el drama (es decir: la tragedia). En realidad lo que se quiere afirmar es que el carácter encubridor que poseen las fuentes de los mitologemas desvían la atención del centro arquetipal de la cuestión, poniendo todo su énfasis, única y solamente, en la narración. Y que si bien la acción escénica está contenida en el relato, el fluir de lo trágico es la suspensión inmanente que propala el conflicto a través del acto narrado. El teatro es in situ, y no antes o después. No obstante, debemos advertir que no es que el mito quiera desviar la atención del que escucha el relato, es simplemente que la superlatividad de lo narrado da al mito un carácter sagrado, místico y religioso.

Estamos pues en una encrucijada de caminos, ya que el mito se revela como una suerte de narración que oculta algo en su fondo (recordemos nuevamente a Edipo ante el oráculo); y en segundo lugar, el mito devela el poder mistérico de su propio correlato. Dicho de otra forma, lo que se narra no es lo esencial, sino lo que oscuramente subyace en lo profundo de lo narrado, pero a lo que no podemos acceder, sino es a manera de "acertijo", o de incógnita, formulándose en una narración. En Helena de Eurípides la obra es en sí la revelación de esta estructura, que se adosan al texto como estructuras isomórficas, mantenidas en fusión por un hilo narrativo, y llevadas en camino por la conexión textual. Veamos que lo primero que ha hecho Eurípides es colocar una historia como "puntapié" inicial del texto, pero no como conflicto escénico sino como espacio de desarrollo del texto:

Helena - He aquí las bellas ondas virginales del Nilo, que, en lugar de la divina lluvia, riega los campos y el país de Egipto cuando la blanca nieve se disuelve. Proteo, cuando vivía, era el rey de esta tierra, habitaba en la isla de Faros y sería soberano de Egipto. Había desposado a una de las doncellas marinas, a Psámate, después de dejar ésta el lecho de Éaco. Y engendró dos hijos en su palacio, un varón, Teoclímeno, [1lamado así porque honró a los dioses todos los días de su vida], lo y una noble doncella, Ido, delicia de su madre mientras fue niña, y a la que, una vez llegada a la edad oportuna para el matrimonio, la llamaron Teónoe, porque sabía las cosas divinas, lo que es y lo que será, prestigios heredados de su abuelo Nereo (1-15).

De manera que no somos la historia, somos el efecto camuflador de la narración propiamente dicha. Coloquemos rápidamente un ejemplo para poder mirar este aspecto mas en concreto. En El último Minotauro, el personaje de Ariadna dice:

\footnotetext{
${ }^{11}$ Ibid. 19.
} 
La imaginación es como una línea de crédito en un banco. Si nos la cortan, vamos a tener que ponernos Teseo y yo a imaginarnos a nosotros mismos. Nos veremos las caras, nuestras verdaderas caras. Si el Minotauro dice la verdad, una vez fuera del mito dejaremos de ser quienes hemos sido para ser quienes somos en realidad ${ }^{12}$.

Ahora bien, el efecto transformado de la narración mítica posee un poder absoluto de trascendencia al punto de que se desplaza en tiempo y espacio sin percatarse de su posteridad. Todo mito no surge a posteriori, sino a priori, está en el centro de una imaginación inconsciente que se muestra por anticipado. Porque al escuchar el mito (a través de la narración) hay una suspensión de la temporalidad. Dicho de otra forma ante el mito estamos en un antes que se puede transformar en un después. El ejemplo típico de esta idea es Edipo. En Edipo Rey la anticipación del oráculo no es una prevención para Edipo. En realidad el oráculo revela las palabras oscuras del mito. Matar a su progenitor y traicionarlo además no con el amor filial, sino con el cuerpo de su madre, es la ruptura de una ley sagrada que los humanos por lo general están tentados a transgredir. Acaso alguien podría creer que Edipo no está consciente de ello. En nuestra tesis lo está, y es precisamente esta causa oculta, no el amor a su madre sino el amor al cuerpo de su madre, y por consiguiente la sustitución del padre por él mismo, que lo lleva al cometido del parricidio y posteriormente al incesto, hecho que como todos sabemos el oráculo le ha revelado. Es pues una escritura sagrada que resulta imposible de romper. Así nos lo hace comprender Silvia Elena Tendlarz, cuando afirma:

Lacan presenta en el Seminario 4 un triángulo inédito hasta entonces. Rompe la pretendida armonía de la relación madre-hijo y afirma que la madre nunca está a solas con el hijo: entre uno y otro siempre está el falo. El niño cobra un valor fálico al identificarse con el objeto de deseo materno. (...) El falo ${ }^{13}$ aquí es definido como un significado, tiene un valor imaginario que se introduce en la metonimia del deseo de la madre. A partir de la distinción entre castración, frustración y privación, Lacan ubica a la frustración como centro de la relación madre-hijo. Pero, añade Miller ("El falo barrado", Elucidación de Lacan, 1998), aquí lo más importante es la frustración de la madre como mujer ${ }^{14}$.

${ }^{12}$ Febres-Cordero 2010: 25.

${ }^{13}$ Aquí se refiere al padre. Hemos suprimido una oración a efectos de nuestro tema que versa lo siguiente: "El cuarto término de esta relación es el padre." Véase Tendlarz (2011): http://www.nel-mexico.org/articulos/seccion/varite/edicion/Sobre-mujeres-madres-yninos/320/Lo-que-una-madre-transmite-como-mujer.

14 Tendlarz (2011) http://www.nel-mexico.org/articulos/seccion/varite/edicion/Sobremujeres-madres-y-ninos/320/Lo-que-una-madre-transmite-como-mujer. 
Edipo como todos los hombres ha violado una ley sagrada. En efecto ha violado la ley, "lo que no se toca", "lo que no se puede ver"15. Pero esto son dramas humanos, lo trágico mismo reside en el hecho y en la acción. En el incumplimiento del deber. Lo trágico del mito (y he allí que el teatro se hace susceptible de portar esta discursividad) está en la narración propia, narración que en tanto tal es escénica y porta teatralidad.

\section{Algunas referencias latinoamericanas al mito en el teatro}

En este punto no nos vamos a extender demasiado, solo queremos hacer una brevísima muestra de cómo en otros autores ha tenido influencia el mito, lo trágico en el teatro latinoamericano. Viendo pues como se ha escrito desde los mitos griegos hasta los mitos propiamente latinoamericanos. A través de la historia del teatro podemos rápidamente ver la trascendencia que tuvo la tragedia griega y sus influencias en la dramaturgia occidental. En el teatro latinoamericano su repercusión también ha sido honda, por supuesto con otros matices y otras metáforas, pero igualmente plena de significación. Así que con el objeto de mostrar solo algunos ejemplos que pueden llevar a ver cómo se han producido y que ello nos de una pequeña muestra de la repercusión que han tenido en nuestro teatro, podríamos nombrar algunos textos y autores que han mirado desde distintas perspectivas el tema. Entre otros los textos que a continuación nombramos: Medea en el espejo de José Triana (Cuba, 1960) ${ }^{16}$; La pasión según Antígona Pérez de Luis Rafael Sánchez (Puerto Rico, 1968); Antigona-Humor de Franklin Domínguez (República Dominicana, 1968); Antígona Vélez de Leopoldo Marechal (Argentina, 1969); La pasión de Pentesilea de Luis de Tavira (México, 1988); Taquilla para palabras no dichas de Johnny Gavlovsky (Venezuela, 1992); El ángel de la culpa de Marco Antonio de La Parra (Chile, 1996); Antígona de José Watanabe (Perú, 2001); Electra Shock de José María Muscari (Argentina, 2003), Antígona y actriz de Carlos Satizábal (Colombia, 2008); Música de Balas de Hugo Salcedo (México, 2012); Yocasta de Héctor Levy-Daniel (Argentina, 2012); etc. Dos casos emblemáticos por lo representacional en el contexto de la literatura hispanoamericana son Los reyes de Julio Cortázar (Argentina, 1970) o Rayito de Estrella (1929), Kukulcán o Soluna del guatemalteco Miguel Ángel Asturias.

[A]sturias como el creador de un teatro-mito moderno latinoamericano influido por las ideas surrealistas, el cual intenta configurar sobre la escena un realismo 'mágico' o 'mítico' que presenta claras afinidades con el aproximadamente simultáneo concepto del 'théatre mythique' ('magique' o 'métaphysique')

\footnotetext{
${ }^{15}$ No en vano recordemos que después Edipo se quitará los ojos como auto castigo del delito cometido.

${ }^{16}$ Estamos tomando la fecha de la primera edición y publicación de las obras.
} 
desarrollado por Artaud en su Théâtre de la cruauté. Especialmente cuadra esto para el ya mencionado proyecto de Artaud La Conquete du Mexique (1932) para el que, junto con fuentes históricas, utilizó también claramente el Popol $V u h$, mencionado por él más tarde con frecuencia pretendiendo en la escena una síntesis no ilusionista entre realidad, mito y magia ${ }^{17}$.

La referencia de Asturias es importante vista desde la perspectiva a través de la cual Asturias trabaja, no sobre la base de un mito griego, sino a partir de temas puntuales que "[s]e corresponden, con la concepción mítica de Kukulcán [...]"18 y su relación con las culturas autóctonas a través de los mitos mayas-quiché.

Lo que hace generalmente cada uno de los autores es que trastoca la estructura fundamental y básica del propio mito y la utiliza de acuerdo con sus lecturas y expectativas. Pero claro que esto supone también construir otra raíz dramática. No obstante, sea que se utilice el mito griego, sea el latinoamericano, el teatro apunta a desmontar la base principal de la narración y utilizarla en su propio beneficio, otorgándole en ocasiones un mayor sentido de teatralidad al drama y haciéndolo por supuesto más trágico. La tragedia no es una estructura que surja por sí sola, viene del propio drama. Es este último que progresivamente y de acuerdo con el desenvolvimiento de los actos se va transformando en tragedia.

\section{MYTHOLOGIA - MYTHLÓGEMA (MYTHOLOGEÍN)}

Desde Platón hasta nuestros días muchos nos han planteado las problemáticas del mito en la historia del pensamiento, entre los más importantes podemos nombrar a George Steiner, Mircea Eliade, El mito del Eterno Retorno (1972), Roland Barthes, Mitologías (1981), Lévi-Strauss, Mito y significado (1987), Antigonas (2000), Bronisław Kasper Malinowski, Frederich Nietzsche, Karoly Kerényi. La cuestión de la mitología es central en la filosofía e incluso por supuesto en la historia.

Hay una problemática de fondo que deseamos resaltar inicialmente y está en relación con lo que Lévi-Strauss nos plantea sobre el problema del significado y el mito. Es cierto que todo mito podría tener una relación isomórfica entre sus elementos que actúan junto a un trozo de sustrato de significado. Estos fragmentos, que son como restos de hilos de la historia remiten (por supuesto no tan obviamente, pero sí parcialmente) a una memoria histórica. Y así como "[n]o puede sustituirse una palabra por cualquier otra palabra, o una frase por cualquier otra frase"19 tampoco resulta posible superponer un mito frente a un hecho histórico; o más bien hacer del significado del primero, el significado del

\footnotetext{
${ }^{17}$ Blüher 1990: 118.

${ }^{18}$ Ibid. 119.

${ }^{19}$ Lévi-Strauss 2002: 232.
} 
segundo. Esto significa que en la base de todo mito hay frases, oraciones, estructuras lingüísticas, que son fijas y que permanecen inamovibles de la memoria. Es así como finalmente opera la construcción de un arquetipo. Esas bases o estructuras lingüísticas fijas se van "solidificando" en la estructura inconsciente hasta que se diseña el arquetipo.

Ahora bien, a pesar de ello, a pesar de sus "diferencias", intrínsecamente tanto mito como historia también poseen estructuras que funcionan isomórficamente y que plantean bases para fundar un sistema de relaciones proclives a vincularse unas a otras. En el fondo de la cuestión, toda mitología (consecuentemente con su respectivo cuerpo de mitos, un mito no es solamente una unidad representativa de sí misma, sino una progresiva “cosmogonía”, junto a un cuerpo diseminado de historias) hace presencia un pequeñísimo y casi consustancial origen real, lo que no supone, por el contrario, que en ese cuerpo de mitos/ mitologías subyace un fondo histórico formalmente significado, constituido. No obstante sin embargo que sí le otorgue un valor de "significación" ${ }^{20}$. Carl Gustav Jung y Károly Kérenyi definen así el valor tanto de la fuente originaria del mito, como de sus elementos constitutivos. En el libro Introducción a la esencia de la mitología: el mito del Niño Divino y los misterios eleusinos se puede leer:

Así pues, (...) no es ya cuestión de si un mito se refiere al solo a la luna, al padre o a la madre, a la sexualidad o al fuego o al agua, sino que se trata únicamente de la paráfrasis y caracterización aproximativa de un núcleo de significado inconsciente. El sentido de ese núcleo no fue nunca consciente y jamás lo será. Sólo ha sido interpretado y seguirá siéndolo siempre, y cada interpretación que se acerca más o menos al sentido oculto (o -desde el punta de vista del intelecto científico- al sin-sentido, lo que viene a ser lo mismo) siempre ha reivindicado para sí, no sólo verdad y validez absolutas sino al mismo tiempo reverencia y devoción religiosas ${ }^{21}$.

En las tres piezas de León Febres-Cordero, el orden irrestricto de la narración escénica precisamente funciona como una estructura de conjuntos paralelos. Los conflictos y el desarrollo de las anécdotas se equiparan (aunque opuestas en conflicto unas de otras) de manera idéntica proveyéndose de sentido en tanto y en cuanto puede ser interpretado. A su vez, este mismo orden isomórfico, antes planteado apunta (por supuesto que no en la idea propia de la escritura dramática) a crear una semblanza de la historia, que tiene su punto de partida en la base de la estructura arquetipal del mito. Tal como afirma Lluis Puebla "no es importante la naturaleza de los objetos pero sí lo es el de sus

${ }^{20}$ Cf. Lévi-Strauss, C., Arruabarrena, H. (1987), Mito y significado. Madrid: Alianza Editorial.

${ }^{21}$ Jung et al. 2004: 101. 
relaciones" ${ }^{22}$. Dicho de otro modo, Febres-Cordero enfrenta a sus personajes polarizando las situaciones y procede tal como el mito mismo con la re-escritura de este (reiteramos lo anteriormente expresado ad infinitum). De tal forma que en su teatro el mito organiza la estructura de la historia como si esta fuera un palimpsesto y a la vez superpone capas sobre capas de texto de manera que en la progresión del drama oculta paulatinamente la fuente de su sustentación, la base de su episteme. Veamos algunos ejemplos de ello. En el monólogo de Teseo (El último minotauro) se hace referencia a ciertas "actitudes" de Ariadna y su relación con el mundo. Teseo afirma:

EL PROBLEMA BÁSICO de mi relación con Ariadna es su inconformidad y que vive en las nubes, siempre buscando lo que no se le ha perdido. Con unas expectativas descomunales. Y no se adapta. Quiere cambiarlo todo, revolucionarlo todo, pero no sabe qué quiere a cambio. Bueno, si uno le pregunta, dice cosas como "ser feliz", "hacer lo que me da la gana", "ser famosa", pero nunca dice cómo lo va a lograr ${ }^{23}$.

Pero un rato antes, Ariadna ha deconstruido y construido no solo los fueros de Teseo, del laberinto y del Minotauro, sino también de sí misma. En este juego de espejos paralelos, isomórficos, cada uno habla del otro reproduciendo el valor singular de la palabra en la metáfora subyacente del mito. En otros términos, se dicen entre sí "hasta del mal que van a morir" y suspenden así el exíguo del juego de la palabra, la fuerza exterior por la fuerza interior que los mueve. Por ello Ariadna no es menos imprudente que el Minotauro, o que Teseo, cuando, citemos:

Nos veremos las caras, nuestras verdaderas caras. Si el Minotauro dice la verdad, una vez fuera del mito dejaremos de ser quienes hemos sido para ser quienes somos en realidad. Pero para mi no hay, no puede haber ya otra realidad que la del mito. ¿Cómo nos las arreglaremos para seguir siendo Ariadna y Teseo sin ser Ariadna y Teseo? ¿Cómo haremos para mantener viva la ilusión de un final, cuando nos liberaremos de todo? ${ }^{24}$

Este sentido de doble identidad: mostrarse como uno, cuando en realidad somos siempre los otros, los otros escondidos bajo máscaras es precisamente la angustia que lleva a Ariadna, la de Febres-Cordero, a estarse sujeta solamente a la realidad que el mito le otorga. No tanto, porque la historia central que envuelve el relato sea de consideración ineludible, sino simplemente porque el

\footnotetext{
${ }^{22}$ Puebla 2009: 4.

${ }^{23}$ Febres-Cordero 1999: 31-32.

${ }^{24}$ Ibid. 31.
} 
mito representa el sustento de su existencia y le garantiza la continuidad de la verdad. La angustia, la inquietud que vive Ariadna por el ¿quiénes seremos? Está presente ante la indiferencia parcial de Teseo hacia ella. Ariadna no lo sabe a ciencia cierta, pero lo presiente.

En el relato original, el valor de Ariadna parece estar supeditado a la fuerza de Teseo (un hombre que por demás no aspira al amor de Ariadna sino el hilo conductor de su destino) aunque está claro que, en una de las versiones, Teseo abandona a Ariadna en la isla Día porque era (según Kerényi) la isla nupcial de Dionisios, y ella sólo proporciona a este valiente el medio a partir del cual Teseo podrá volver salir del laberinto.

Es cierto también que Ariadna supone el amor de Teseo y a la vez el amor del Minotauro. La capacidad seductora de la mujer es un motivo que parece estar presente en muchas de las tragedias griegas, Medea por Jasón, Antígona por Hemón, pero también Electra por su padre, Yocasta la madre de Edipo por Edipo mismo, etc. Aquí la Ariadna de Febres-Cordero también juega sobre el interés del deseo que su cuerpo proporciona a Teseo. En uno de los fragmentos donde Febres-Cordero pone énfasis sobre el tema de la corporalidad y la capacidad de seducción de la mujer, Ariadna explica:

Ser Ariadna en el mito es ser el cuerpo de Ariadna. Y, ¿qué se hizo mi cuerpo, mi cuerpo verdadero, mi cuerpo de niña alegre y despreocupada? Que me olvide de él, me dijo un día el Minotauro. Que aquí, en el mito, el cuerpo no es de carne y hueso, es otra cosa, más bien como una energía de la imaginación ${ }^{25}$.

O un poquito más adelante:

Un cuerpo que aún siente los besos que nunca me dieron, los abrazos a los que no me entregué, las noches que aguardé, inmóvil y perfumada en la cama, hasta la madrugada, a que no llegara nadie ${ }^{26}$.

porque el mito atenta contra toda voluntad de cuerpo. La angustia de Ariadna por el cuerpo de Teseo, y en lo oculto también por el cuerpo del Minotauro, atiende a una necesidad lacaniana de construcción de la subjetividad. El cuerpo en tanto un en-sí es como consecuencia de esta inmaterialidad una subjetividad. Está claro que ni el dramaturgo, ni el personaje son capaces de elaborar (teatralmente hablando) esta disquisición. No porque no lo pudieran hacer, sino simplemente porque este no es su fin, su destino. $\mathrm{O}$ al menos no lo hacen como materia filosófica, ya que el personaje es un vehículo incorpóreo que se materializa desde la experiencia del actor. Esta ausencia metafísica del mito, o

\footnotetext{
${ }^{25}$ Ibid. 26.

${ }^{26}$ Ibid. 26-27.
} 
del mito como revelador no sólo de la experiencia, sino de la existencia nos la termina explicando una vez más Ariadna, cuando un fragmento más adelante de los citados previamente dice:

Y, ¿qué se hizo mi cuerpo, mi cuerpo verdadero, mi cuerpo de niña alegre y despreocupada? Que me olvide de él, me dijo un día el Minotauro. Que aquí, en el mito, el cuerpo no es de carne y hueso, es otra cosa, más bien como una energía de la imaginación ${ }^{27}$.

Pero el mito no es tragedia de ninguna forma. El mito es sólo eso mito, una historia singular, significativa, pero que figura en el inventario de la memoria de manera un tanto borrosa. Lo que deviene en trágico es sí, el resultado a posteriori, aunque su esencia sea puramente irreductible. De tal manera que como característica central se ponen en juego así dos categorías importantes para la constitución de su tragedia; en primer lugar aquello que se denomina como: Menschein (Ser-hombre) y en segundo lugar el Dasein (constituirse en sí). Ambos elementos-categorías están interconectados interna, intrínseca e interiormente, y esta tríada (que es similar en su conjunto, pero diferente a la vez) se vincula a través de la pulsión y el deseo.

Esto significa, por un lado, ser o constituirse en una presencia en el mundo (tanto Ariadna, Teseo y el Minotauro así lo desean imperiosamente), y por otro, interrogar la inmanencia de ese significado (de la misma manera para sí, como para los otros). En la obra, tanto Menschein como Dasein se bifurcan entre los tres personajes, que enfrentados en un conflicto solo resoluble por el valor de fuerzas superiores, les pone en juego a través de sus propias pulsiones. El mito del Minotauro tiene para ese doblez: mentira y realidad, sueño y creación. E1 ejemplo central nos lo trae una vez más la propia Ariadna, cuando afirma:

Llevo mucho tiempo esperando a que Teseo me libere, llevo siglos esperando por mi libertad. Quiero ser la absoluta dueña de mis actos: hacer, por fin, lo que me dé la real gana, sin que nadie se meta en mis asuntos. Estoy harta de que todo sea como dice el Minotauro. Estoy harta y amargada de hilar e hilar para que nunca pase nada. Son miles de años, miles de miles de años, millones de años sin que nada pase de verdad. Y no es posible que después de tanto sacrificio, resulte que esto no sea más que un cuento, un cuento ridiculísimo, además. Porque eso de que yo esté aquí eternamente hilando el hilo con el que Teseo estará eternamente buscando a un Minotauro que va a estar eternamente "un pasito más allá" de su perseguidor... eso es de una ridiculez supina. Y sin embargo, heme aquí, incapacitada para hacer otra cosa, paralizada por completo, alelada. Y ya no aguanto más. El Minotauro me

\footnotetext{
${ }^{27}$ Ibid. 26.
} 
dice que son frivolidades, pero quiero salir a bailar por ahí hasta las mil y una, quiero que alguien me mire con ojos de embeleso y me quiera raptar para sí, y me arrebate, y me enamore y me transporte a todos mis sueños irrealizados... y que ese alguien, ese desconocido, sea, por supuesto, Teseo. Mi detestado Teseo. El hombre que me arruinó la vida, que me engaña una y otra vez, que me promete la redención salir del laberinto, salir del laberinto para siempre y ser rica, muy rica, con limousines enormes, con todas las casas que quiera regadas por el mundo, con trajes y carteras y zapatos y todos los accesorios de Chanel. Ese hombre maldito no da pie con bola. No se entera ni de lo que está pasando en el laberinto. Sin embargo, su imbecilidad me mantiene intacta, me mantiene Ariadna, me permite seguir siendo inconmensurable, siempre a punto de ser redimida ${ }^{28}$.

Menschein es también caerse, de lo que se puede deducir que resulta necesario descender para poder ser, para constituirse. Puesto que el hombre ya no puede comportarse como un "sujeto", es una persona venida a menos, y de ningún modo es un sujeto nietzscheano (léase: superhombre), de allí que Teseo caiga, irremediablemente en la catástrofe. No obstante es un hecho que no le sobreviene solo a Teseo, también ocurre con el Minotauro y Ariadna quienes también caen. Y, solo cayendo, yendo abajo, derrumbándose, tumbándose, solo así podrán levantarse (Dasein). Es por ello que la catástrofe no es en el sentido de lo trágico, un final total. Para nosotros corresponde al espíritu agonístico que dominaba entre los griegos y que Febres-Cordero lo pone en práctica constantemente con sus personajes en cada una de las obras mencionadas al principio. Aquí vamos a dar un breve salto para ejemplificarlo desde la tragedia de Clitemnestra (2010), cuando Egisto hablando de su propio drama de vida y tratando de explicar por qué pone afrentas a su relación con Clitemnestra, por qué en la vida diaria de los amantes se han impuesto ese destino incólume, agonístico en el que a pesar de odiarse deben, deciden permanecer juntos, dice: “(...) y desde el hueco fondo de su desesperanza surgió, como un incontenible torrente de osadía, la terca pasión de Clitemnestra por el novio de su hija" ${ }^{29}$ o un poco antes ha dicho: "Ella me odia, pero el odio es una de las formas del amor, su forma más secreta, más intensa, más permanente, la que más nos ata al otro" ${ }^{30}$. Está claro que Febres-Cordero utiliza este procedimiento casi con cada una de sus obras. El sistema consiste en "reencarnar" el conflicto de sus personajes en la fuente original del mito y de lo trágico, pero en esencia a través del relato. Esto entendemos que lo hace con el objetivo de lograr la cualidad dramática que el texto teatral exige (por un lado); y por otro retoma este sentido doble que "caída-ascenso-caída" o

\footnotetext{
${ }^{28}$ Ariadna, Escena II: Ibid. 25.

${ }^{29}$ Monólogo de la Escena IV, Acto I: Ibid. 50-51.

${ }^{30}$ Monólogo de la Escena IV, Acto I: Ibid. 50.
} 
lo que es lo mismo las categorías de las que venimos hablando Menschein-Dasein.

En El último minotauro ocurre otro tanto. La fuerza dialéctica del Menschein-Dasein se impone en los personajes y frente al carácter de los personajes. Aunque en la pieza procedimentalmente no resulte así, sino todo lo contrario. Veamos por ejemplo la crisis de derrota que sufre Ariadna al verse totalmente embrollada en su propia madeja de conflictos, citemos:

Siempre había soñado con el Minotauro, con Teseo, con mi hilo, con el laberinto ... pero empecé a soñar con las sombras indefinidas de otros personajes. Uno de ellos era el de una princesa a la que un vestido envenenado le consumía el cuerpo. Fue una pesadilla terrible. Comencé a considerar más seriamente la posibilidad de la existencia de otros mitos, otros mitos fuera del nuestro. Mitos enteramente distintos al laberinto en que nos encontramos los tres aquí, pero relacionados entre sí. La idea de la existencia de una serie de mitos comunicados en cadena basta el principio de los siglos me parecía atroz. Aún no la acepto del todo: termino pensando que es un invento del Minotauro, una audaz artimaña de su parte para confundirnos y escapar de Teseo. Sin embargo, de ser así... de haber otros mitos, otros habitantes de mitos, entonces tendría que reconocer que yo, Ariadna, soy un personaje más de un mito cualquiera. Y no Ariadna, ¡A Ariadna!, la única, la Sola, la Paciente, la Ariadna de toda la vida. La que espera a que un día todo cambie, cuando Teseo le muestre la negra cabeza ensangrentada del Minotauro, y pueda salir de aquí, salir de este laberinto para siempre, y comenzar a vivir, a vivir la nueva vida, la vida verdadera, esa que nos ha sido prometida si le damos caza al Minotauro. Y esa vida que tanto ansío, ese anhelo por la vida que llevaré cuando ya no esté atrapada en un mito, es mi vida de Ariadna ${ }^{31}$.

Así podemos ver que las pérdidas son siempre una consecuencia de la pulsión y del síntoma. Lo que nos hace presumir varios elementos constructivos de esta tragedia moderna:

1. Todo mito es una inversión;

2. Si, como nos explica Jung, "Todo cuanto está en el inconsciente quiere llegar a ser acontecimiento, y la personalidad también quiere desplegarse a partir de sus condiciones inconscientes y sentirse como un todo" ${ }^{32}$, entonces la actuación del imaginario es la elaboración de ese inconsciente.

Es desde este lugar a partir del cual surge precisamente esa duplicidad en la pregunta. Todo el mecanismo propositivo del plan escénico y dramatúrgico se sostiene (en el interior del texto) sobre la base propiamente dicha del mito en

\footnotetext{
${ }^{31}$ Febres-Cordero 2010: 24.

32 Jung 1971: 17.
} 
tanto tal. El mito representa una caída, una pérdida y una angustia a futuro, Edipo nos lo ha reconocido claramente y aunque conoce su destino ulterior decide emprender viaje, entre otras cosas, motivo de la vergüenza que le aviene tener "conocimiento" tanto del asesinato de padre, así como de llevar a cabo una relación incestuosa con su madre. No obstante, no es inversamente proporcional a la representación en el texto de Febres-Cordero. En el caso del dramaturgo venezolano, en realidad el Minotauro siempre ha estado en el mundo de abajo y sucumbe en este, por el empecinamiento de Ariadna, la tozudez de Teseo, la voluntad humana que es capaz de arrasar con todo frente a la inteligencia y sabiduría de los dioses. La estructura dramática de la tragedia muestra al fin la poderosa convicción que lleva en sí su discursividad: diálogo y subtexto están bien "agarrados de la mano" porque el mito sólo tiene algunas vías para explicarse a sí mismo. Y en medio de la derrota que sufre el sujeto en el contexto de su existencia, reafirmando la voluntad por encima de todas las cosas en el sello superhombre-agón los personajes no solo son capaces de enfrentarse con su propio destino, sus dudas, sus ausencias, sus dolores, sino que son capaces también de ir más allá de sus límites y hacer frente también al otro en las diferencias.

E1 Minotauro, a pesar de que frecuentemente ha sido atacado (tanto por Teseo como por Ariadna), aún se considera fuerte, no nos lo dice, pero así lo muestra y así igualmente Febres-Cordero lo pone dentro del relato. Lo hace con una voz. Le da Voz a un personajes que históricamente no solo ha permanecido oculto en el laberinto, sino al que no se le ha permitido hablar, "contar su versión de los hechos". Y como tal esta es una voz que otros (ya habíamos hablado de Los reyes al inicio de este trabajo) no muestran, porque tanto en el mito, como en su diversas representaciones, el Minotauro es un ser mitológico "mudo", o al que se le obliga a permanecer "mudo". Esta situación no hace más que delatar en su textualidad una fuerza que proviene de la conformación por una cierta aristocracia. Los elementos conflictivos del drama empiezan a funcionar, no a partir del pretexto dramático (sustrato propio del mito) sino en función de la ley que mueve a sus personajes. Veamos entonces el ejemplo que en la cuarta y última escena de la pieza, que corresponde con el segundo monólogo del Minotauro, este nos asegura:

COMO TODOS LOS DIAS cuando empiezan a cantar los primeros pájaros en las suaves copas de los cipreses, y el cielo es una delgada manta humeante que se deshace, ya he tomado mi asiento aquí, en el centro del laberinto. Pero esta vez tengo miedo. Últimamente no logro dormir más que unas cuántas horas, y me despierto a cada rato sin reconocer dónde estoy. Quisiera pasar el día echado, pero no aguanto mucho esa postura tampoco. Es la espalda, que ya no me sostiene y se resiente, como si hubiera cargado sobre ella todo el peso del laberinto. Han terminado por consumirme estos muros que el tiempo se ha encargado de reforzar, y que han estado temblando toda la noche. A través del boquete que se abrió en uno de ellos se ve una hilera casi infinita 
de minotauros que se extiende y serpentea como un riachuelo y se pierde en lontananza. Los he visto erguirse y resoplar y patear iracundos, blandiendo negras y gigantescas hachas dobles, hambrientos de la tierna carne de los sacrificios que se les deben. Minotauros que braman con la fuerza y el estrépito de mil terremotos juntos. Me acuclillo dentro del boquete para disimularme en el muro y, tal vez, evadir la embestida del furor divino que ya sacude la cima de los montes más lejanos. El temblor de tierra viene anunciado por un alboroto de ruidos metálicos, de ritmos extraños que provienen de los últimos arrabales, de chirridos y de golpes de tambor. La algarabía de los sangrientos cazadores anuncia que ha llegado el momento. ¡Viene, viene como un ahogo liberador, con la fuerza de un zarpazo, el momento que pensé que no llegaría nunca porque Teseo no daría conmigo, porque Ariadna no lo dejaría! ¡Pero el momento ha llegado, lo anuncian ya los bramidos, lo anuncia el olor de la sangre que está apunto de ser vertida! ¡Qué lástima me da sentir que sería posible postergar este instante, respirar un poquito más antes de que las altas sombras de las hachas oculten el tenue cielo de la madrugada! De cuclillas, dentro del boquete en el muro, no quiero cerrar los ojos para abrazar con la mirada, por última vez, la suavidad de las lejanas colinas sagradas y los tiernos cipreses, delgados como cirios, y la luna, la piadosa luna que se tiñe ahora de la sangre que brota de mi cuello cuando, volteado en seco el testuz hacia atrás, me degüellan y descuartizan. Como un eco, el golpe se repite y me desgarra el vientre para sacar las entrañas y ponerlas al fuego, y me arranca las piernas y los brazos, y hace crujir mi espalda como cruje el espinazo de un cervatillo bajo la garra del leopardo. La cabeza aún se mueve y en el aire los ojos abiertos del pelele beben las últimas imágenes amadas, y sus oídos los últimos bramidos, los balbuceantes bramidos que cobraron vida propia antes de sucumbir, mientras la sangre lo purificaba todo: el barro, las piedras, las dulces laderas de olivos y más allá, el mar dormido, y por encima de las altas cumbres la manta humeante de la mañana. Chillando y voceando resuena por el valle la salvaje algarabía, mientras la danza serpentea y se pierde en la distancia. Chillando y voceando, las estrellas enrojecidas caen como hojas en el firmamento. Sobre una vara, en el centro del laberinto, la cabeza de toro aún chorrea sangre ${ }^{33}$.

Y tanto en Ariadna, así como en Teseo o en el Minotauro, Febres-Cordero siempre nos pone a uno como espejo de otro. Pero también este recurso lo ha hecho en las otras de sus dos piezas que por falta de espacio no hemos trabajado aquí. Lo ha hecho con el personaje de Clitemnestra y Egisto, en Clitemnestra; o con, por ejemplo, Penteo y Ágave en Penteo.

Finalmente, se debe hacer notar que Febres-Cordero toma los relatos más antiguos, accede a las referencias esquileanas apartándose del camino central a lo que nos ha propuesto Esquilo, y lleva la "historia" un poco más allá, desde

${ }^{33}$ Escena IV, último monólogo de la obra, y segundo del Minotauro: Febres-Cordero 2010: 34-35. 
el mismo instante en que trastoca la fuente básica ritual y religiosa que tratan de inspirarnos obras como la esquileana. Hace un juego de doble inversión, y puestos espejo contra espejo, la imagen se multiplica ad infinitum perdiéndose la esencia básica de la verdad. El mito sustrae y contrae la historia para depositarla en el inconsciente colectivo de toda la comunidad. Retoma no solo al personaje y a la obra para redescubrir las metáforas de una construcción "de sujeto/de sujetos", en tanto una realidad propiamente individual, sino que también redescubre la memoria colectiva de nuestros países. Así por ejemplo en el primero de los 4 monólogos presentados en El último minotauro, el Minotauro dice: "LO TENGO CLARO. Lo tengo clarísimo. Yo no soy un Minotauro, menos aún el Minotauro. Yo sólo me Presto al juego, a hacer de, a Pretender.”; y acto seguido Ariadna (en el segundo de los monólogos) dice: "NO TENGO NADA CLARO. No tengo claro ni siquiera si seguiré siendo Ariadna. El Minotauro me ha hecho perder hasta esa elemental certeza. Dice que sólo somos actores" ${ }^{44}$; o en el tercer monólogo, nos apela Teseo: "LO QUE NO TENGO para nada claro es cómo vamos a llegar a fin de mes. No me puedo explicar en qué se nos fueron los reales. No sé ni con qué vamos a cubrir el pago mínimo de las tarjetas”35.

Tal como ya hemos aseverado, el mito siempre lleva consigo un mensaje oculto y al mismo tiempo una moraleja, que convierte a la "narración" de este, en un hecho fáctico. Pero la fuerza narrativa y el poder laberíntico del mitologema nos hace correr el riesgo, según lo que plantea Kerényi, de perdernos en el propio "laberinto" de la trama. El poder en sí mismo del procedimiento narrativo/ dramático está en el centro de atracción de la figura del dédalo. En todos y cada uno de ellos (Teseo, Ariadna, el Minotauro) el laberinto funciona así como un eje de poder que domina sobre la figura y el pensamiento de los hombres. Todo el poder del Dios está concentrado en el orden cerrado de la estructura maciza, penetrable del dédalo pero de la que es imposible escapar cuando se quiere. Pero es exactamente allí dónde radica toda la fuerza del mitologema. Por un lado el poder de seducción y atracción que el dédalo supone, y por otro la ambición individual que domina en cada uno de los personajes que nos antepone en el camino hacia una actitud sagrado-religiosa de sumisión ante los acontecimientos. Los hombres están supeditados a los designios de los dioses, que son quienes introducen en el universo del laberinto a ellos. Tal como Kerényi nos afirma:

La amenaza, en otros términos, es perder de vista la unidad general de las facetas, dejándose atraer por las vicisitudes de las narraciones concretas englobadas en el mito, o al menos en la forma más completa y compleja que el mito asume. Es decir, existe el riesgo de seguir las numerosas "historias" en su devanarse y entrecruzarse, perdiendo el hilo continuo que hace de ellas una

\footnotetext{
${ }^{34}$ Febres-Cordero 2010: 23.

${ }^{35}$ Ibid. 27.
} 
sola "historia". Y como se ve, mucho más allá de un puro juego de palabras, esto es ya un problema laberíntico ${ }^{36}$.

Febres-Cordero, tanto como sus personajes, se pierden en el esquema propio del laberinto, construyendo a través de una compleja madeja la forma de un sujeto venido totalmente degradado. En el principio originario del mitologema (el sustrato mismo del relato mítico), Teseo, Ariadna y el Minotauro son fuentes inagotables de sabiduría y pensamiento religioso. En la obra del autor venezolano estos valores están destruidos, sus palabras, sus historias muestran que vivimos en una época de decadencia. $\mathrm{Y}$ es que precisamente parece que la re-representación de este acontecimiento no puede redescubrirse sino por fuerza de una angustiante autodestructividad.

\section{A manera de Conclusión}

Todo mito basa persistente la existencia en su fuerza indestructible que es a partir de Dionisios (según nos lo explica Kerényi) la raíz de la vida misma, la base arquetipal de sus signos y símbolos son la fuente de su poder y el carácter de su irreductibilidad. Las variaciones pueden ser casi infinitas (por no querer afirmar tajantemente que lo son) pero su sentido último es reiterativo, vuelve a comenzar con cada segmento, con cada porción de vida humana. Allí reside su esencia, en esa capacidad "autocombustible" que procede de la base de su génesis. En la dramaturgia latinoamericana los mitos no se reducen a la nada, sino que al contrario actúan con la potencia y la fuerza de su propia existencia. E1 teatro en América Latina parece reactualizar no el acontecimiento propiamente dicho, sino el sentido último del valor de la significación de la obra misma y de la trascendencia que el relato adquiere a medida que se pierde en el pasado y trata de reactualizarse en el presente. En efecto León Febres-Cordero opera con ese mecanismo que tanto la tragedia como el mito le aportan. A pesar de ser "historia antigua" su irreductibilidad es esencial y le permite firmemente retornar revitalizando la historia no solo en su pasado más lejano, sino en el presente que vivimos.

\footnotetext{
${ }^{36}$ Kerényi 2006: 10.
} 


\section{Bibliografía}

S/N (2010), Entrevista a León Febres-Cordero: autor de "Teatro" y "En torno a la tragedia y otros ensayos". Agathos: Atención sociosanitaria y bienestar 4: 68-77.

Barthes, R. (1981), Mitologías. México: Siglo XXI.

Blüher, K. A. (1990), "La recepción de Artaud en el teatro latinoamericano", in Toro, F. de (ed.), Semiótica y Teatro Latinoamericano. Ottawa, Ont., Galerna, IITCTL: 113-131.

Cortázar, J. (1970), Los reyes. Buenos Aires: Editorial Sudamericana.

Eliade, M. (1972), El mito del eterno retorno; arquetipos y repetición. Madrid: Alianza Editorial.

Medina González, A., López Férez, J. A. (1977a), Eurípides, Helena. Madrid: Editorial Gredos.

Medina González, A., López Férez, J. A. (1977b), Eurípides. Tragedias. III. Madrid: Editorial Gredos.

Febres-Cordero, L. (2010a), El último minotauro, in Teatro. Madrid, Verbum: 15-36.

Febres-Cordero, L. (2010b), Clitemnestra, in Teatro. Madrid, Verbum: 37-84.

Febres-Cordero, L. (2010c), Penteo, in Teatro. Madrid, Verbum: 199-230.

Febres-Cordero, L. (2010d), Teatro. Madrid: Verbum.

Jung, C. G. (1971), Recuerdos, sueños, pensamientos. Barcelona: Seix Barral.

Jung, C. G., Kerényi, K., Kiemann, B., Gauger, C. (2004), Introducción a la esencia de la mitología: el mito del niño divino y los misterios eleusinos. Madrid: Ediciones Siruela.

Kerényi, K. (1997), Los dioses de los griegos. Caracas: Monte Ávila Editores Latinoamericana.

Kerényi, K. (2006), En el laberinto. Madrid: Siruela.

Kerényi, K. (1998), Dionisios: raíz de la vida indestructible. Barcelona: Herder.

Kerényi, K., Kiemann, B. (2011), Imágenes primigenias de la religión griega. interpretación griega de la existencia humana IV. México D.F.: Sexto Piso.

Kerényi, K. (1999), La religión antigua. Trad. Adan Kovacsics, Barcelona: Herder.

Lévi-Strauss, C. (2002), "El encuentro del mito y de la ciencia”, in Páez Díaz de León, L. (ed.), Vertientes contemporáneas del pensamiento social francés: ensayos y textos. México, Escuela Nacional de Estudios Profesionales Acatlán, Programa de Apoyo a Proyectos Institucionales de Mejoramiento de la Enseñanza: 227-232. 
Lévi-Strauss, C., Arruabarrena, H. (1987), Mito y significado. Madrid: Alianza Editorial.

Lluis-Puebla, E. (1990), Álgebra homológica, cohomología de grupos y k-teoría algebraica clásica. Wilmington (U.S.A.): Addison-Wesley Iberoamérica.

Lluis-Puebla, E. (2009), Teoría de grupos: un primer curso. México: Sociedad Matemática Mexicana.

Marechal, L. (1965), Antígona Vélez. Buenos Aires: Ediciones Citerea.

Páez Díaz de León, L. (2002), Vertientes contemporáneas del pensamiento social francés: ensayos y textos. México: Escuela Nacional de Estudios Profesionales Acatlán, Programa de Apoyo a Proyectos Institucionales de Mejoramiento de la Enseñanza.

Salcedo, H. (2012), Música de balas: texto dramático en un acto. México, D.F.: Universidad Autónoma Metropolitana.

Steiner, G. (2000), Antígonas: la travesía de un mito universal por la bistoria de Occidente. Barcelona: Gedisa.

Tendlarz, S. E. (2011), "Lo que una madre transmite como mujer" [NEL México (Nueva Escuela Lacaniana del Campo Freudiano)]. Recuperado a partir de http://www.nel-mexico.org/articulos/seccion/varite/edicion/ Sobre-mujeres-madres-y-ninos/320/Lo-que-una-madre-transmitecomo-mujer. 